\title{
Work In Progress: Development and Evaluation of an Online Chemical En- gineering Bridging Course
}

\author{
Dr. Hassan Golpour, North Carolina State University \\ Dr. Matthew Cooper, North Carolina State University
}

Dr. Matthew Cooper is an Associate Professor (Teaching Track) in the Department of Chemical and Biomolecular Engineering at North Carolina State University where he teaches Material and Energy Balances, Unit Operations, Transport Phenomena and Mathematical / Computational Methods. He is the recipient of the 2014 NCSU Outstanding Teacher Award, 2014 ASEE Southeastern Section Outstanding New Teacher Award, and the 2016 ASEE ChE Division Raymond W. Fahien Award. Dr. Cooper's research interests include effective teaching, conceptual and inductive learning, integrating writing and speaking into the curriculum and professional ethics.

\section{Dr. Lisa G. Bullard, North Carolina State University}

Dr. Lisa Bullard is an Alumni Distinguished Undergraduate Professor and Director of Undergraduate Studies in the Department of Chemical and Biomolecular Engineering at North Carolina State University. She received her BS in Chemical Engineering from NC State and her Ph.D. in Chemical Engineering from Carnegie Mellon University. She served in engineering and management positions within Eastman Chemical Company from 1991-2000. A faculty member at NC State since 2000, Dr. Bullard has won numerous awards for both teaching and advising, including the ASEE Raymond W. Fahien Award, the John Wiley Premier Award for Engineering Education Courseware, NC State Faculty Advising Award, National Effective Teaching Institute Fellow, NC State Alumni Outstanding Teacher Award, George H. Blessis Outstanding Undergraduate Advisor Award, and the ASEE Southeastern Section Mid-Career Teacher Award. She is a member of the editorial board for Chemical Engineering Education and serves a Director of the Chemical Engineering Division of ASEE. She will be a co-author, along with Dr. Richard Felder and Dr. Ronald Rousseau, of the 4th edition of Chemical Process Principles. Dr. Bullard's research interests lie in the area of educational scholarship, including teaching and advising effectiveness, academic integrity, process design instruction, and the integration of writing, speaking, and computing within the curriculum. 


\title{
Work-in-Progress: Development and Evaluation of an Online Chemical Engineering Bridging Course
}

\begin{abstract}
This paper discusses the development and assessment of an online chemical engineering bridging course, which is a two-semester course designed to prepare students with backgrounds in chemistry, biology and other non-chemical engineering fields for graduate study in chemical engineering. Although it is not equivalent to a four-year degree in chemical engineering, the course aims to furnish students with sufficient background to successfully undertake graduate classes offered by a chemical engineering program. This course will also provide a suitable option for employees in technical fields who desire understanding of core chemical engineering concepts.
\end{abstract}

Using information technology and multimedia tools, short topic modules have been designed which use video lectures, worked screencasts of example problems and homework solutions, and conceptual testing instruments. Students will be able to communicate and discuss their ideas and problems using live and archived group chat-room applications to practice working in an interactive group work environment with other students and the course instructor.

We plan to utilize evidence-based evaluation techniques to assess the effectiveness of the course (and individual features of the course) toward student learning. Possible evaluation methods will be discussed, and feedback from the audience will be encouraged.

Keywords: Chemical Engineering, Engineering Education, Bridging Course, Online Course, Continuing Education

\section{INTRODUCTION}

Chemical engineering graduate programs often receive applications from students whose undergraduate degree is in chemistry, physics, biology, or another engineering discipline. These typically are excellent students with undergraduate research or work experience, but their lack of chemical engineering background can present challenges in their successful acceptance to and progress in a chemical engineering graduate program. Some of these students are asked to take several undergraduate courses as prerequisites to prepare them for graduate work.

Michigan State University (MSU) has offered a spring-summer online "bridging” course, Foundations in Chemical Engineering, for this target audience since $2000,{ }^{1}$ and faculty at NC State have directed multiple prospective graduate students to this resource. AIChE Academy ${ }^{2}$ and $\mathrm{ACS}^{3}$ also offer a large variety of workshops and online courses related to chemical engineering, but each of these courses are shorter (e.g. 30 total hours of instruction) and so on their own would not be expected to offer the same depth as a two-semester university bridging course spanning 45 or more hours of instruction. These AIChE/ACS courses also do not count on their own as college credit, though in some cases universities may grant one university credit hour for every 100 hours of online AIChE courses completed. ${ }^{4-6}$ Besides prospective graduate 
students, the course may also provide a suitable option for employees in technical fields who desire understanding of core chemical engineering concepts.

This presentation will describe the development and assessment of a two-semester (fall-spring) online chemical engineering bridging course that is part of an initiative at NC State to broaden its reach of distance education. Since this bridging course is offered on a different timetable (fallspring) than the MSU course (spring-summer), starting in Fall 2018, it expands course offerings for interested students. Prospective students who complete the course sequence will be able to count the two courses, 6 elective credit hours, toward a MS Chemical Engineering degree at NC State, which may be attractive to prospective graduate students.

\section{COURSE DESIGN AND DESCRIPTION}

A significant initial challenge in developing the course was to determine the content. This required condensing six undergraduate courses (material and energy balances, two semesters of thermodynamics, transport phenomena, and reactor design) down to two. It was determined that a good first step was to interview the instructors of the graduate core courses to determine the essential elements of the undergraduate content required for success at the graduate level. These graduate faculty were a valuable resource in pruning the list of topics to a manageable number. They also provided feedback on topics that tend to be challenging for non-chemical engineering students, such as transport. The graduate faculty also provided input regarding how to sequence the material in a logical manner. Rather than cover the topics sequentially (i.e. as separate and distinct topics, as they are in the standard curriculum and also the MSU course ${ }^{1}$ ), the graduate instructors suggested that some of the thermodynamics content be integrated into material and energy balances, and cover the foundational topics of both thermodynamics and transport in Course 1. Course 2 would then address more application-focused content in both thermodynamics and transport in addition to kinetics and reactor design.

After this discussion it was determined that this online CHE bridging course will be offered in two consecutive semesters (fall and spring) at the authors' institution as a distance education course. The two-semester bridging course, entitled "Core ChE Concepts: I and II", is divided into four categories spread over the two semesters, as described in Table 1. As noted previously, the topics shown in Table 1 are not presented sequentially but are integrated over both semesters.

One open question is whether students taking an online course will choose to purchase each of the textbooks described in Table 1 or look for other ways to access the material. This will affect the level of detail and background required in the course material provided. One possibility is to make select chapters available through the library's on-line reserves. Another future possibility is to construct a custom textbook for the course.

With course content identified, the next step in the course development was securing a grant from the NC State's DELTA (Distance Education and Learning Technology Applications) program which supports faculty in creating an online distance education course. Through this program web education developers and architects provide support with an emphasis on innovation in the use of technology and pedagogy in online teaching and learning. The grant supported three members of the DELTA team who worked with the authors to develop a template within a learning 
Table 1. Course Contents.

\begin{tabular}{|c|c|c|}
\hline Module & Selected Topics & Suggested Textbook \\
\hline Material and Energy Balance & $\begin{array}{l}\text {-Fundamentals of Material Balances } \\
\text {-Single-Phase Systems } \\
\text {-Multi-Phase Systems } \\
\text {-Energy and Energy Balances } \\
\text {-Energy Balances on Non-Reactive Processes } \\
\text {-Energy Balances on Reactive Processes }\end{array}$ & $\begin{array}{l}\text { Elementary Principles } \\
\text { of Chemical Processes, } \\
\text { 4th Edition } \\
\text { Felder, Rousseau, \& } \\
\text { Bullard }\end{array}$ \\
\hline Thermodynamics & $\begin{array}{l}\text {-First and Second Laws of Thermodynamics } \\
\text {-Application of Thermodynamics to Flow Processes } \\
\text {-Production of Power from Heat } \\
\text {-Refrigeration and Liquefaction } \\
\text {-Thermodynamic Properties of Fluids } \\
\text {-Solution Thermodynamics } \\
\text {-Chemical Reaction Equilibrium } \\
\text {-Mixing Properties } \\
\text {-Phase Equilibrium }\end{array}$ & $\begin{array}{l}\text { Introduction to } \\
\text { Chemical Engineering } \\
\text { Thermodynamics, } \\
\text { 8th Edition } \\
\text { Smith, Van Ness, } \\
\text { Abbott, \& Swihart }\end{array}$ \\
\hline Transport Phenomena & $\begin{array}{l}\text {-Momentum Transport } \\
\text {-Heat Transfer (Forced and Natural Convection, } \\
\text { Conduction, and Radiation) } \\
\text {-Mass Transfer }\end{array}$ & $\begin{array}{l}\text { Transport Phenomena, } \\
\text { 2nd Edition } \\
\text { Bird, Stewart, \& } \\
\text { Lightfoot }\end{array}$ \\
\hline Reaction and Reactor Design & $\begin{array}{l}\text {-Mole Balances } \\
\text {-Reactor Sizing } \\
\text {-Rate Law and Stoichiometry } \\
\text {-Isothermal Reactor Design }\end{array}$ & $\begin{array}{l}\text { Elements of Chemical } \\
\text { Reaction Engineering } \\
\text { 5th Edition } \\
\text { Fogler }\end{array}$ \\
\hline
\end{tabular}

management system to organize the course content and help students effectively navigate the site. This support was invaluable to the instructors and has resulted in a much more professional and well-structured final product than the authors would have achieved on their own.

Individual course modules have specific learning objectives, lectures, homework, and conceptual quizzes borrowed from either the AIChE Concept Warehouse ${ }^{7}$ or LearnChemE.com ${ }^{8}$. The lecture portion of each module usually consists of several topics which will be taught through series of short video lessons (2 to 10 minutes) featuring a presentation from an instructor. A smart tablet in the recording studio is used to annotate the presentations and direct the students' attention to key points. Example problems and homework solutions are presented to students in the form of screencasts. In order for students to communicate with each other, a live group chat room will accompany each module. Although students will not be allowed to directly discuss answers to homework, quizzes or the final exam, in the chat-room students could interact with other students in the class using the typing option or voice talk to share their ideas, concerns, and questions about each module or homework. This will provide practice students with practice working in an interactive group work environment. The chat room will be recorded for further use by students, especially those who were not able to be online at the time of the live chat. Office hours will also be provided online, though selection of the program/media through which to offer office hours and the chat room is still under debate - feedback on ideal resources to offer these accompaniments is welcomed. In total, there will be approximately 15 - 20 homework assignments, 7 - 10 concept quizzes, and one final exam each semester.

The initial focus in assessment for the first offerings of the course in Fall 2018 and Spring 2019 is to collect baseline data which can then be compared with equivalent data collected in later 
semesters. This method will allow evaluation of the effectiveness of any changes made in later semesters against a baseline to inform statistical comparisons. Data is expected to be collected through course evaluations, student surveys, academic records, scores on homework and exams, and final grades. Potential data measures may include:

- Academic performance: grades in the bridging course, direct evidence used to assess skill attainment in subject areas, and performance in students’ later CBE graduate courses (for students who continue at NC State)

- Student demographics: undergraduate degree discipline, professional experience

- Course experience and engagement: average time to complete each module, time spent on homework, engagement with content/materials, engagement with other students and the instructor

- Learning perceptions: feedback on the effectiveness of the course content (videos, homework/examples, lectures and readings, online learning site)

- Motivation/readiness: individual's perspective on the importance of mastering the material, valuation of time and effort required to learn the material, and enjoyment from engaging with the material

Suggestions from the audience on other assessments to consider are welcomed.

\section{NEXT STEPS AND DESIRED FEEDBACK FROM WORK-IN-PROGRESS SESSION}

At the time of this writing, the course described in still in development but we anticipate that the content will be complete by the ASEE Annual Conference. Decisions still to be made include the software used to offer group student chats and as instructor office hours, as well as other items described in this paper. In the first offering of the course in Fall 2018-Spring 2019, a key objective will be to validate content choices, ensure that the material is presented at the right level of detail and pace for students enrolled in the course, and determine the efficacy of any improvements to the online interface students use in the course. It is hoped that feedback from ASEE attendees will help identify appropriate assessment methods toward these goals.

One idea for future evolution of the course is the possibility of customizing the course content for students in order to allow them to focus on the skill areas they need. A pre-test and/or transcript review would provide input to instructors regarding which modules the student needs to complete, so that students who already have a strong background in one area can concentrate on modules directed toward their personalized gaps in understanding. This feature would be unique and could distinguish the course from other bridging courses.

\section{REFERENCES}

1. C.T. Lira, R.M. Worden, and D. Briedis, "Graduate Bridging and Continuing Education Using the Internet," Chemical Engineering Education, 35(4), 230-235 (Fall 2001).

2. AIChE Academy, at https://www.aiche.org/academy last accessed March 08, 2018.

3. ACS Course Catalog, at http://proed.acs.org/course-catalog/types/online-courses/ last accessed March 12/2018.

4. AIChE Academy eLearning, at https://www.aiche.org/academy/eLearning?utm_source=aichesites\&utm_medium=link\&utm_campaign=eLearn 
ingnav\&f\%5B0\%5D=sm_aiche_academy_delivery\%3ACourses\&f\%5B1\%5D=sm_aiche_academy_delivery\% 3ACourses/eLearning\%20course Last accessed March 12/2018.

5. Proffesional Development Program - An Overview, at http://www.oregon.gov/tspc/Pages/FAQs_PDUs_Overview.aspx Last accessed March 12/2018.

6. International Association for Continuing Education and Training, at https://www.iacet.org/ last accessed March $12 / 2018$.

7. AIChE Concept Warehouse, at http://jimi.cbee.oregonstate.edu/concept_warehouse/, last accessed January 25, 2018.

8. LearnChemE, Instructor resources, at http://www.learncheme.com/conceptests, last accessed January 25, 2018. 